\title{
A Comparison of the Effects of Different Types of Laryngoscope on the Cervical Motions: Randomized Clinical Trial
}

\author{
Alkin Çolak ${ }^{1}$, Elif Çopuroğlu ${ }^{1}$, Ali Y1lmaz ${ }^{2}$, Sevtap Hekimoğlu Şahin ${ }^{1}$, Nesrin Turan $^{3}$ \\ ${ }^{1}$ Department of Anesthesiology, Trakya University Faculty of Medicine, Edirne, Turkey \\ ${ }^{2}$ Department of Anatomy, Trakya University Faculty of Medicine, Edirne, Turkey \\ ${ }^{3}$ Department of Biostatistics, Trakya University Faculty of Medicine, Edirne, Turkey
}

Background: The rate of cervical injury among all trauma patients is $3.1 \%$. The most important point during intubation of those patients is not to increase the cervical injury.

Aims: In this study, we hypothesize that there will be a minimal cervical extension during a laryngoscopy with the use of optical view laryngoscopes.

Study Design: Prospective, randomized clinical trial.

Methods: One hundred and fifty adult patients with ASA physical status I to III were enrolled in our study. After routine anesthesia induction, we randomly assigned the patients into three groups according to the type of laryngoscope. Macintosh type, Truview $\mathrm{EVO}^{\circledR}{ }^{\circledR}$ type and Airtraq ${ }^{\circledR}$ type laryngoscopes were used in Group DL $(n=50)$, Group TW $(n=50)$ and Group ATQ $(n=50)$, respectively. After applying general anesthesia induction and mask ventilation, all of the patients were positioned in the neutral position. An inclinometer was placed on the forehead of the patients. Then, the extension angle during intubation and the Cormack-Lehane Score were measured and the time to intubation was recorded.

Results: One of the 50 patients in the DL Group, 2 of the 50 patients in the TW Group, and 4 of the 50 patients in the ATQ Group were excluded from the study because of the failure of intubation at defined times. The angle of cervical extension during laryngoscopy was found to be $27.24 \pm 6.71,18.08 \pm 7.53$, and $14.54 \pm 4.09$ degrees in the Groups DL, TV and ATQ, respectively; these differences also had statistical significance $(\mathrm{p}=0.000)$. The duration of intubation was found to be $13.59 \pm 5.49$, $23.60 \pm 15.23$, and $29.80 \pm 13.82$ seconds in Groups DL, TV and ATQ, respectively ( $\mathrm{p}=0.000)$.

Conclusion: A minimal cervical motion was obtained during tracheal intubation with the use of Truview EVO2 ${ }^{\circledR}$ and Airtraq ${ }^{\circledR}$ types of laryngoscope compared with the Macintosh laryngoscope. (ClinicalTrials.gov Identifier: NCT02191904).

Keywords: Airtraq $^{\circledR}$, airway management, intratracheal equipment, intubation, Macintosh, Truview EVO2 ${ }^{\circledR}$
The incidence of cervical spine injury (CSI) among all trauma patients was $3.1 \%$ between 2002 and 2006 according to data of the National Trauma Data Bank of the American College of Surgeons (1).

Ensuring minimal cervical motion during the intubation of trauma patients is important for the prevention of CSI or further deterioration of existing CSI (2).
Intubation is required to secure the airway in patients during anesthesia management or mechanical ventilation in intensive care units. Laryngoscopes are the tools used for intubations. The most widely used laryngoscope type is one with a Macintosh blade. However, various types of laryngoscopes have been developed for use in cases of difficult intubation, the intubation of patients with head and neck trauma, or for intuba-

Address for Correspondence: Dr. Alkin Çolak, Department of Anesthesiology, Trakya University Faculty of Medicine, Edirne, Turkey Phone: +90 5052310473 e-mail: alkincol@yahoo.com

Received: 23.04.2014 Accepted: 15.12.2014 • DOI: 10.5152/balkanmedj.2015.15335

Available at www.balkanmedicaljournal.org

Colak A, Copuroglu E, Y1lmaz A, Sahin SH, Turan N. A comparison of the effects of different types of laryngoscope on the cervical motions: randomized clinical trial. Balkan Med J 2015;32:176-82. 


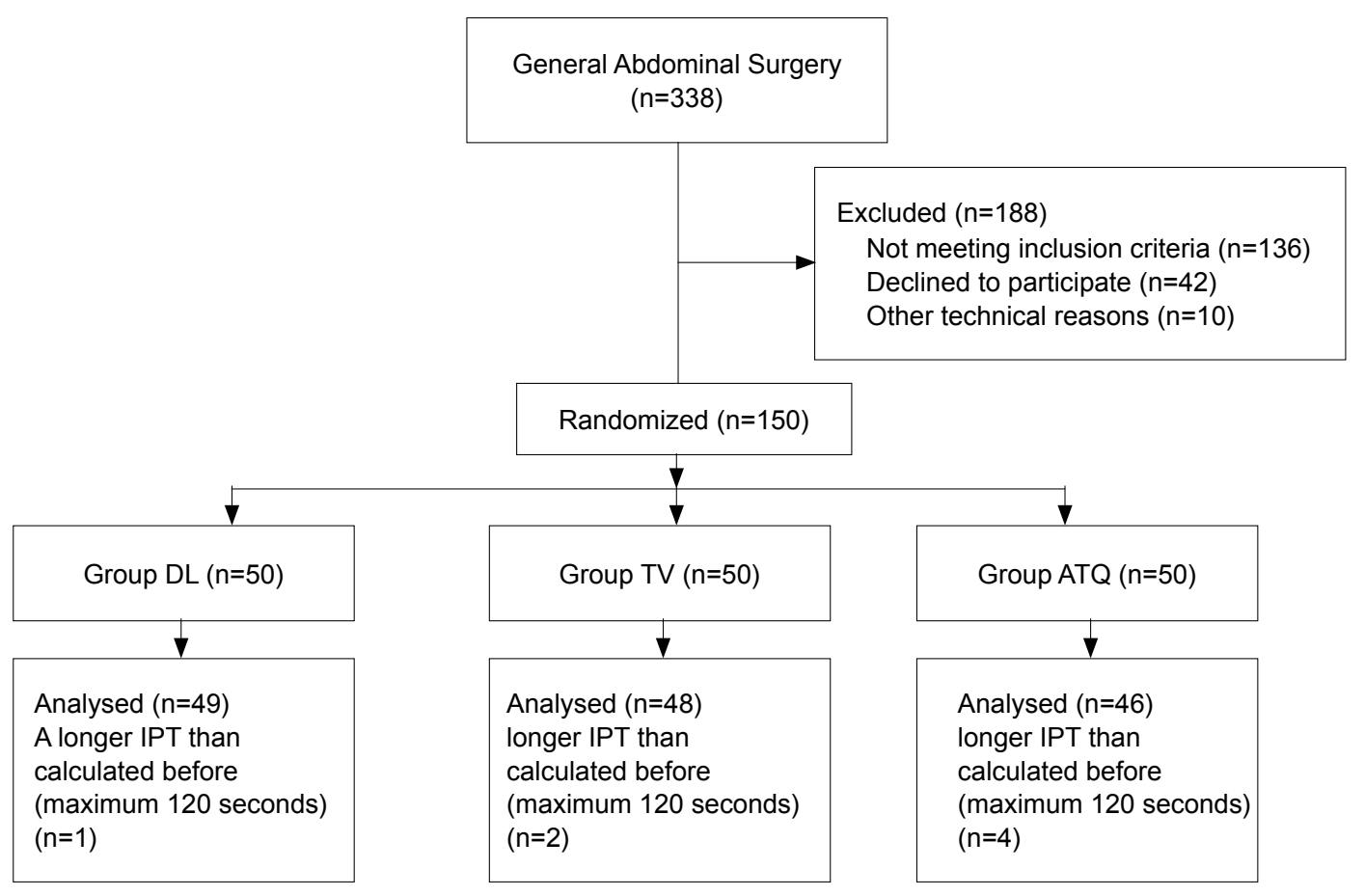

FIG. 1. Flow chart of patient enrolment and analysis

tion attempts carried out by inexperienced individuals. Truview EVO2 ${ }^{\circledR}$ and Airtraq ${ }^{\circledR}$ are newly developed laryngoscopes, which are integrated with an optical view system $(3,4)$.

The Truphatek Truview EVO $2^{\circledR}$ (Truphatek International Ltd, Netanya, Israel) is a recently introduced, easy viewing type of laryngoscope, modified from the blades of Macintosh-type laryngoscopes; these have an angle of $46^{\circ}$ at the end of blade and include a camera system that magnifies the image (3).

The Airtraq ${ }^{\circledR}$ laryngoscope (ATQ; King Medical Systems, Newark, DE) is also a newly developed type of laryngoscope, which includes an optical imaging system. There is a channel on the device for the placement of the endotracheal tube. The endotracheal tube is inserted into the channel before the laryngoscope (4). It has been reported that Airtraq is a novel, single use laryngoscope which provides glottis display without any deviation in the normal position of the oral, pharyngeal or tracheal axes (5).

In the literature, there are many studies comparing the effects of these newly developed laryngoscopes on cervical motions in different scenarios with cadavers and normal patients (4,6-10). However, in these studies, individual vertebral motion was reported during placement of the tube, while the angulation of the head and neck and the difficulty of intubations were not clear.

In this study, our first hypothesis was that cervical extension during endotracheal intubation in Truview EVO2 ${ }^{\circledR}$ and Airtraq $^{\circledR}$ types of laryngoscopes is less than that when using a Macintosh laryngoscope. The second hypothesis was that the endotracheal intubation time is similar to that of the Macintosh, which is used more often.

\section{MATERIALS AND METHODS}

After obtaining approval from Trakya University Local Ethical Committee, Edirne, Turkey and written consent from patients participating in the study, those patients who were to undergo general anesthesia for abdominal surgery, with an American Society of Anesthesiologists physical status of I to III, and who were aged between 20 and 75, were included in this study, between January 2011 and December 2012.

Patients were enrolled to this study in a randomized manner, from 150 patients who were to be operated upon in general surgery clinics. The randomization was done by selecting envelope. Patients were randomly assigned into three groups using the sealed envelope method according to the laryngoscope type; here, we used Macintosh type, Truview EVO2 ${ }^{\circledR}$ type and Airtraq ${ }^{\circledR}$ type laryngoscopes in the direct laryngoscopy Group $(\mathrm{DL} ; \mathrm{n}=50)$, Truview EVO $2^{\circledR}$ Group (TV; $\left.\mathrm{n}=50\right)$ and Airtraq ${ }^{\circledR}$ Group (ATQ; $\mathrm{n}=50$ ), respectively (Figure 1).

Our exclusion criteria were a history of emergency intubation or difficult intubation, a body mass index higher than 35 or a rheumatologic disease that causes limitation of cervical motion, a previous history of cervical operation or tumor, trau- 




FIG. 2. Head in the neutral position

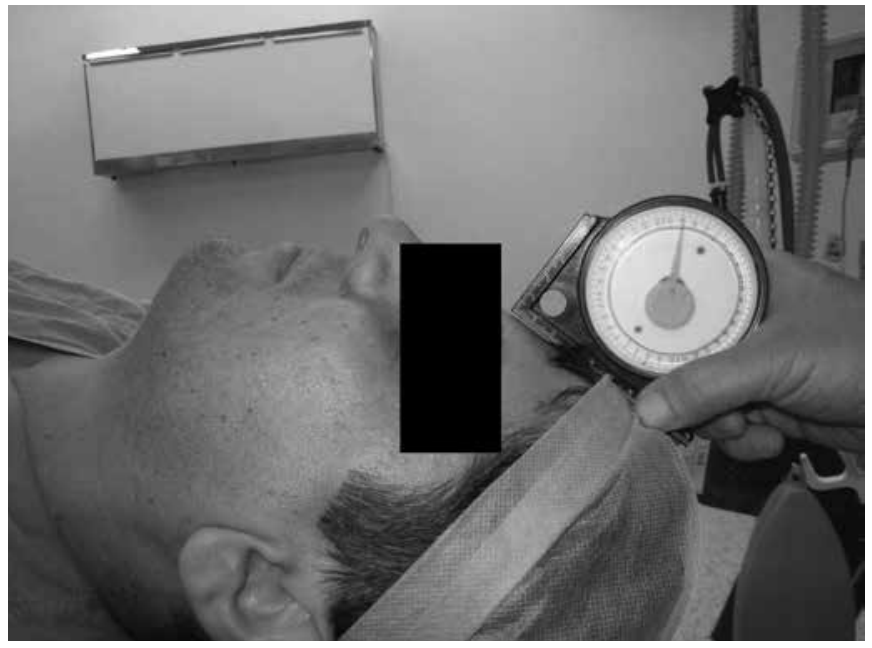

FIG. 3. Inclinometer measurements from the head in extension

ma or infection on upper airway, and the absence of teeth. Anthropometric measurements such as tiromental (thyroidea and gnathion) and sternomental (sternal and gnathion) distances, inter-incisor gap (between the lower and upper incisor teeth), neck circumference (at the level of the thyroid cartilage), and lower face height (between gnathion and subnasale) were measured and recorded by an anatomist the night before the operation. We excluded those patients with a tiromental distance of less than $6 \mathrm{~cm}$, a sternomental distance of less than 12 $\mathrm{cm}$, an inter-incisor gap of less than $3 \mathrm{~cm}$, a neck circumference of more than $42 \mathrm{~cm}$ and a lower face height of between 5.5 and $8 \mathrm{~cm}$. In addition, the Modified Mallampati scores were evaluated and recorded by an anesthesiologist.

In the operating room, standard anesthesia monitoring was performed with the 3-way electrocardiogram (ECG), peripheral non-invasive blood pressure (NIBP) and oxygen saturation $\left(\mathrm{SpO}_{2}\right)$.
Anesthesia induction was performed with 2 to $2.5 \mathrm{mg} / \mathrm{kg}$ propofol intravenously, and then a compound of 2-2.5\% sevoflurane $+50 \% \mathrm{O}_{2}+50 \% \mathrm{~N}_{2} \mathrm{O}$ was inhaled and 0.5 to $0.6 \mathrm{mg} /$ $\mathrm{kg}$ rocuronium was given intravenously. Five minutes after the administration of rocuronium, the head of the patients was fixed in neutral position. While the ventilation with face mask, different manipulations could be performed to the head. Therefore, neutral position was applied to the head before the laryngoscopy. In this procedure, the head was stabilized as the infraorbital edge and tragus is perpendicular to the ground. An inclinometer (a 360 degree angle gauge) was placed on the forehead of the patients, so that the tip of the inclinometer fit the glabellar line (Figure 2, 3). The inner diameters of the intubation tubes used for females and males were 7 to $7.5 \mathrm{~mm}$ and 8 to $8.5 \mathrm{~mm}$, respectively. The intubation stylet was inserted into the intubation tubes in Group TV before the process was initiated. After applying a lubricant-free local anesthetic agent to the outer surface of the intubation tube, the tube was placed into the Airtraq ${ }^{\circledR}$ laryngoscope in Group ATQ before initiation of the process. The maximum angle of cervical extension was measured by an inclinometer. The head was neutrally positioned and the degree that the inclinometer showed was recorded. Then, the maximum degree shown by the inclinometer during laryngoscopy and tracheal intubation was recorded. The maximum angle of cervical extension was measured by subtracting the first and last recorded degree.

Also laryngoscopic view and Intubation Difficulty Scale (IDS) scores were assessed and recorded for all patients. An IDS score of 0 to 4 suggests easy intubation, and $\geq 5$ denotes a difficult intubation.

The duration from the laryngoscope blade passing the lips and the placement of the tube into trachea was recorded as the intubation process time (IPT).

All intubations were performed by one anesthesiologist (Dr. Colak) to eliminate differences among the anesthesiologists' experiences. If the IPT was more than 120 seconds, the patients were ventilated for 1 minute with a face mask, and then intubation was performed using a fiberoptic laryngoscope for unsuccessful ones in Groups DL, TV and ATQ; those patients were excluded from the study. Finally, all of the patients were intubated.

\section{Statistical analyses}

Statistical analyses were performed using the STATISTICA AXA 7.1 (StatSoft Inc., Tulsa, OK, USA) statistical software. The suitability of the data within the normal distribution was assessed using the one-sample Kolmogorov Smirnov test. For intergroup comparisons, the one-way analysis of variance (ANOVA) and post hoc Bonferroni tests were performed for patients within normal distribution, while Kruskal Wallis variance analysis and 
TABLE 1. Demographic data and anthropometric measurements

\begin{tabular}{|c|c|c|c|c|c|}
\hline & & $\begin{array}{c}\text { Group DL } \\
(\mathrm{n}=49)\end{array}$ & $\begin{array}{c}\text { Group TV } \\
(\mathrm{n}=48)\end{array}$ & $\begin{array}{c}\text { Group ATQ } \\
(\mathrm{n}=46)\end{array}$ & $\mathrm{p}$ \\
\hline \multicolumn{2}{|c|}{ Age (yr) } & $49.69 \pm 16.04$ & $48.21 \pm 15.06$ & $47.70 \pm 16.86$ & 0.861 \\
\hline \multicolumn{2}{|c|}{ Weight (kg) } & $76.02 \pm 15.33$ & $79.27 \pm 18.96$ & $72.30 \pm 11.23$ & 0.162 \\
\hline \multicolumn{2}{|c|}{ Height $(\mathrm{cm})$} & $170.98 \pm 8.55$ & $172.73 \pm 10.05$ & $170.85 \pm 8.19$ & 0.522 \\
\hline \multicolumn{2}{|c|}{$\operatorname{Sex}(F / M)$} & $24 / 25$ & $23 / 25$ & $23 / 23$ & 0.980 \\
\hline \multirow[t]{4}{*}{ MMS } & 1 & 20 & 11 & 15 & \multirow{4}{*}{0.068} \\
\hline & 2 & 17 & 25 & 27 & \\
\hline & 3 & 11 & 9 & 4 & \\
\hline & 4 & 1 & 3 & 0 & \\
\hline \multicolumn{2}{|c|}{ LFH (mm) } & $71.67 \pm 6.58$ & $71.90 \pm 6.50$ & $70.13 \pm 7.01$ & 0.294 \\
\hline \multicolumn{2}{|c|}{$\mathrm{CC}(\mathrm{mm})$} & $421.98 \pm 57.00$ & $415.10 \pm 56.01$ & $406.20 \pm 49.45$ & 0.369 \\
\hline \multicolumn{2}{|c|}{ SMD (mm) } & $160.16 \pm 20.20$ & $166.35 \pm 18.52$ & $162.26 \pm 18.05$ & 0.267 \\
\hline \multicolumn{2}{|c|}{ TMD (mm) } & $99.18 \pm 14.96$ & $96.15 \pm 15.80$ & $96.96 \pm 17.48$ & 0.527 \\
\hline \multicolumn{2}{|c|}{ IIG (mm) } & $31.67 \pm 5.56$ & $31.42 \pm 4.07$ & $32.43 \pm 3.36$ & 0.488 \\
\hline
\end{tabular}

the Mann Whitney U test with Bonferroni correction $(\mathrm{p} / 3=0.016)$ was performed for patients out of normal distribution. Pearson chi square test and the two-sample Kolmogorov-Smirnov test were performed for qualitative data. Descriptive statistics were presented as mean $\pm \mathrm{SD}$ and median (min-max). $\mathrm{p}<0.05$ and $\mathrm{p}<0.016$ for the results of Mann Whitney U test with Bonferroni correction were accepted as statistically significant.

\section{RESULTS}

One hundred and fifty patients were included in this study. One of the 50 patients in Group DL, 2 of the 50 patients in Group TV, and 4 of the 50 patients in Group ATQ were excluded from the study because of a longer IPT than calculated before (maximum 120 seconds). There was no difference between the groups of excluded patients $(\mathrm{p}=0.350)$.

There was no statistically significant difference between demographic data and anthropometric measurements and Mallampati Scores $(\mathrm{p}=0.168)$ (Table 1).

Cormack-Lehane Scores were statistically different between groups ( $\mathrm{p}=0.001$ ). Cormack-Lehane scores of the DL Group were found to be significantly higher than those of the TV and ATQ Groups ( $p=0.001$ and $p=0.002$, respectively), whereas there was no statistically significant difference between Group TV and Group ATQ ( $\mathrm{p}=0.906$ ) (Table 2).

The angle of cervical extension during laryngoscopy was found to be $27.24 \pm 6.71^{\circ}, 18.08 \pm 7.53^{\circ}$, and $14.54 \pm 4.09^{\circ}$ in Group DL, TV and ATQ, respectively; these differences also
TABLE 2. Cormack-Lehane Scores between the Groups

\begin{tabular}{lccccc}
\hline & & $\begin{array}{c}\text { Group DL } \\
(\mathrm{n}=49)\end{array}$ & $\begin{array}{c}\text { Group TV } \\
(\mathrm{n}=48)\end{array}$ & $\begin{array}{c}\text { Group ATQ } \\
(\mathrm{n}=46)\end{array}$ & $\mathrm{p}$ \\
\hline & 1 & 29 & 42 & 40 & \\
Cormack- & 2 & 15 & 6 & 5 & 0.001 \\
Lehane & 3 & 5 & 0 & 1 & \\
& 4 & 0 & 0 & 0 & \\
\hline
\end{tabular}

TABLE 3. Intubation Process Times and maximum angulation of head and neck for all Groups

\begin{tabular}{lcccc}
\hline & $\begin{array}{c}\text { Group DL } \\
(\mathrm{n}=49)\end{array}$ & $\begin{array}{c}\text { Group TV } \\
(\mathrm{n}=48)\end{array}$ & $\begin{array}{c}\text { Group ATQ } \\
(\mathrm{n}=46)\end{array}$ & $\mathrm{p}$ \\
\hline $\begin{array}{l}\text { Intubation process } \\
\text { time (s) }\end{array}$ & $13.59 \pm 5.49$ & $23.60 \pm 15.23$ & $29.80 \pm 13.82$ & 0.000 \\
$\begin{array}{l}\text { The angle of cervical } \\
\text { motion (degree) }\end{array}$ & $27.24 \pm 6.71$ & $18.08 \pm 7.53$ & $14.54 \pm 4.09$ & 0.000 \\
\hline
\end{tabular}

Data are reported as mean (SD)

had statistical significance $(\mathrm{p}=0.000)$. The angle of cervical extension in Group DL was found to be significantly higher than that of Group TV and Group ATQ ( $p=0.001$ and $p=0.001$, respectively). There was no statistically significant difference between Group TV and Group ATQ ( $\mathrm{p}=0.021$ ) (Table 3).

The IPTs were $13.59 \pm 5.49$ seconds, $23.60 \pm 15.23$ seconds, and 29.80 \pm 13.82 seconds in Groups DL, TV and ATQ, respectively. The differences in these durations were statistically significant $(\mathrm{p}=0.001)$. The IPTs in Group DL were found to be significantly lower than those of Group TV and Group ATQ ( $p=0.001$ and $p=0.001$, respectively), and the IPTs in Group TV were found to be significantly shorter than those of Group ATQ $(\mathrm{p}=0.005)$ (Table 3).

There was no statistically significant difference between the groups of patients that were found to have IDS score equal to or more than $5(\mathrm{p}=0.998)$. When the tests included in IDS were examined one by one, a statistically significant difference was found between N3, N4 and N5 ( $\mathrm{p}=0.001, \mathrm{p}=0.001$ and $\mathrm{p}=0.016$, respectively). $\mathrm{N} 3$ was found to be significantly higher in Group TV than Group DL and Group ATQ ( $p=0.001$ and $\mathrm{p}=0.001$, respectively), and was found to be significantly higher in Group ATQ than Group DL ( $\mathrm{p}=0.009)$. N4 was found to be significantly higher in Group DL than Groups TV and ATQ ( $\mathrm{p}=0.001, \mathrm{p}=0.011$, respectively), while there was no statistically significant difference between Groups TV and ATQ ( $p=0.485$ ). N5 in Group DL was found to be significantly different than in Group TV ( $p=0.009$ ), while there was no statistically significant difference between Group DL and Group ATQ, and Group TV and Group ATQ ( $\mathrm{p}=0.084$ and $\mathrm{p}=0.289$, respectively) (Table 4).

No complications such as laceration, throat bleeding, dental fracture, or blood on the blade of the laryngoscope were observed in all intubations. 
TABLE 4. IDS Scores between the Groups

\begin{tabular}{|c|c|c|c|c|}
\hline & $\begin{array}{c}\text { Group DL } \\
(\mathrm{n}=49)\end{array}$ & $\begin{array}{c}\text { Group TV } \\
(\mathrm{n}=48)\end{array}$ & $\begin{array}{l}\text { Group ATQ } \\
(n=46)\end{array}$ & $\mathrm{p}$ \\
\hline IDS $\geq 5$ & 3 & 2 & 1 & 0.998 \\
\hline N1 & $0.00(0-1)$ & $0.00(0-1)$ & $0.00(0-1)$ & 0.776 \\
\hline $\mathrm{N} 2$ & $0.00(0-0)$ & $0.00(0-1)$ & $0.00(0-1)$ & 0.169 \\
\hline N3 & $0.00(0-1)$ & $1.00(0-1)^{*}$ & $0.00(0-1)^{\# \dagger}$ & 0.001 \\
\hline N4 & $0.00(0-2)$ & $0.00(0-1)^{*}$ & $0.00(0-2)^{\#}$ & 0.001 \\
\hline N5 & $0.00(0-1)$ & $0.00(0-1)^{\#}$ & $0.00(0-1)$ & 0.016 \\
\hline N6 & $0.00(0-1)$ & $0.00(0-1)$ & $0.00(0-1)$ & 0.906 \\
\hline N7 & $0.00(0-0)$ & $0.00(0-0)$ & $0.00(0-0)$ & 1.000 \\
\hline
\end{tabular}

\section{DISCUSSION}

Different types of laryngoscopes (Truview EVO2 ${ }^{\circledR}$, Glidescope $^{\circledR}$, Pentax AWS ${ }^{\circledR}$, Airtraq $^{\circledR}$, etc.) were developed for use in a variety of situations such as difficult intubations, trauma patients, or to make the intubation process easier for inexperienced hands. In our study, we compared the Truview EVO2 ${ }^{\circledR}$ and Airtraq types of laryngoscopes with the Macintosh-type laryngoscope which has been considered to be the gold standard, in terms of intubation difficulties, maximum angle of head and neck extensions, intubation process times, and complications.

Cervical extension, airway tissue deformation, spine and airway soft tissue properties and applied force for laryngoscopy are important for cervical motion during endotracheal intubation (11). The view of the glottis and intubation with videolaryngoscopes can be successful with 30 to $50 \%$ less cervical extension compared with a Macintosh laryngoscope (4).

Truview EVO2 ${ }^{\circledR}$ laryngoscopes have been reported to have advantages in patients with a low risk of difficult intubation when compared to the Macintosh-type laryngoscope $(12,13)$, whereas, in some case reports, patients with difficult intubation with Macintosh laryngoscopes have been reported to have successful intubations with Truview EVO2 ${ }^{\circledR}$-type laryngoscopes $(14,15)$.

The angle of cervical motion during laryngoscopic intubations has been examined in different trials $(9,10)$. However, these studies were mostly focused on movements of single cervical vertebrae, not total movements. Unlike other studies, we evaluated maximum cervical motion from the beginning of laryngoscopies to the end of the intubations in a large number of patients. We have found the angulation values to be $27.24 \pm 6.71^{\circ}$ with Macintosh, $18.08 \pm 7.53^{\circ}$ with Truview $\mathrm{EVO}^{\circledR}{ }^{\circledR}$, and $14.54 \pm 4.09^{\circ}$ with Airtraq ${ }^{\circledR}$-type laryngoscopes. Similar to other studies, the angulation values were found to be higher with Macintosh laryngoscopes than other types in our study.

Kulkarni and Tirmanwar have also suggested better glottis visualization when using Truview EVO2 ${ }^{\circledR}$ compared to Macintosh (16). McElwain and Laffey (17) compared the CormackLehane scores with Airtraq ${ }^{\circledR}$ and Macintosh in 90 patients undergoing general anesthesia with tracheal intubation for surgical procedures, and reported better scores with Airtraq ${ }^{\circledR}$. In accordance with the literature, Cormack-Lehane scores in our study were found to be better with Truview $E V O 2^{\circledR}$ and Airtraq ${ }^{\circledR}$ than Macintosh.

Malik et al. (7) reported a significantly longer time for intubation with the Truview EVO $2^{\circledR}$ laryngoscope $[15 \mathrm{sec}(10-$ 19); $17 \mathrm{sec}(12-24)]$ than with the Macintosh laryngoscope [10 $\mathrm{sec}(7-16) ; 10 \mathrm{sec}(8-18)]$ on manikins with a normal airway and with normal airway and cervical rigidity. They also reported an increase in the success of intubation, and decrease in intubation time with the Truview EVO $2^{\circledR}$ laryngoscope than with Macintosh-type laryngoscope on scenarios on manikins with tongue edema and with tongue edema and also cervical rigidity (7). Arora et al. (18) found the intubation time to be $10.9 \pm 2.1$ seconds in Macintosh and 12.1 \pm 3.8 seconds in Truview EVO2 ${ }^{\circledR}$ during normal endotracheal intubation.

Turksta et al. (10) reported an intubation time of $8.8 \mathrm{sec}$ (6.7-10.6 sec) with Airtraq ${ }^{\circledR}$ and $12.4 \mathrm{sec}(10.2-14.5 \mathrm{sec})$ with Macintosh; this difference was not statistically significant. Maharaj et al. (19) reported that the intubation process time with Airtraq $^{\circledR}$ was statistically shorter than that with Macintosh $(13.2 \pm 5.4 \mathrm{sec}$ vs $20.3 \pm 12.2 \mathrm{sec})$, and they also found a statistically significant decrease in IDS scores (0 versus 2 ).

Malik et al. (8) reported that IDS scores were higher with a Macintosh laryngoscope, and that the intubation time with a Macintosh laryngoscope $(13.9 \pm 9.2 \mathrm{sec})$ was significantly shorter than that of with Truview EVO2 ${ }^{\circledR}(22.5 \pm 7.5 \mathrm{sec})$. They reported a lower Cormack and Lehane score with Truview $\mathrm{EVO} 2^{\circledR}$ than with a Macintosh laryngoscope.

The intubation process times with Macintosh, Truview $\mathrm{EVO}^{\circledR}{ }^{\circledR}$ and Airtraq ${ }^{\circledR}(13.59 \pm 5.49 ; 23.60 \pm 15.23 ; 29.80 \pm 13.82$ seconds, respectively) in our study were also consistent with those in the literature. Timanaykar et al. (20) reported a prolonged time for intubation of $33.62 \pm 5 \mathrm{sec}$. with Truview $\mathrm{EVO}^{\circledR}$ and $23.11 \pm 5 \mathrm{sec}$. with Macintosh in their study comparing two types of laryngoscopes. The intubation times in that study were slightly longer than the IPTs in our study. The reason for this longer intubation time is that they used the time with capnograph wave to determine the duration of intubation after intubation.

The sum of IDS scores did not differ between the groups in terms of difficult intubations in our study. However, Cormack 
Lehane scores (IDS N4) were found to be significantly higher in the Macintosh group. This is because of the visualizations from different angles provided by laryngoscopes with optical cameras.

One of the limitations of our study was the lack of blinded assessments of the type of laryngoscopes by the anesthesiologist. In addition, all intubations were performed by single experienced anesthesiologists; this may therefore result in different outcomes from those of less experienced healthcare workers. Moreover, this study excluded potential difficult intubations. However, the aim of the study attempts to tackle cervical extension, which is only a concern in the potentially unstable cervical spine when manual in-line stabilization is held. The clinical significance of the results found from this study over cervical traumatic patients can be tested.

In conclusion, it was determined that the amount of maximum cervical motion during intubation with Truview EVO2 ${ }^{\circledR}$ and Airtraq ${ }^{\circledR}$ laryngoscopes was less than with Macintosh-type laryngoscopes, but the longer duration of implementation was not clinically significant.

Ethics Committee Approval: Ethics committee approval was received for this study from the ethics committee of Trakya University Local Ethical Committee (EKAEK 2010/01).

Informed Consent: Written informed consent was obtained from patients who participated in this study.

Peer-review: Externally peer-reviewed.

Author contributions: Concept - A.Ç., A.Y., E.Ç., S.H.Ş., N.T; Design - A.Ç., A.Y., E.Ç., S.H.Ş., N.T.; Resource - A.Ç., A.Y., E.Ç.; Materials - A.Ç., A.Y., E.Ç.; Data Collection \&/or Processing - A.Ç., A.Y., E.Ç., S.H.Ş.; Analysis \&/or Interpretation - A.Ç., A.Y., E.Ç., S.H.Ş., N.T.; Literature Search - A.Ç., A.Y.; Writing - A.Ç., A.Y., E.Ç., S.H.Ş.; Critical Reviews - A.Ç., A.Y., E.Ç.

Conflict of Interest: No conflict of interest was declared by the authors.

Financial Disclosure: The authors declared that this study has received no financial support.

Editor-in-Chief's note: One of the authors of this article, Sevtap Hekimoğlu Şahin is the member of the editorial board of Balkan Medical Journal. However, she did not take place at any stage on the editorial decision of the manuscript.

\section{REFERENCES}

1. Branco BC, Plurad D, Green DJ, Inaba K, Lam L, Cestero R, et al. Incidence and clinical predictors for tracheostomy after cervical spinal cord injury: a National Trauma Databank review. J Trauma 2011;70:111-5. [CrossRef]

2. Crosby ET. Airway management in adults after cervical spine trauma. Anesthesiology 2006;104:1293-318. [CrossRef]

3. Carlino C, Pastore JC, Battistini GM, Cancellieri F, De Caria $\mathrm{D}$, Ruggieri N, et al. Training resident anesthesiologists in adult challenging intubation comparing TruView EVO2 and Macintosh laryngoscope: a preliminary study. Minerva Anestesiol 2009;75:563-7.

4. Turkstra TP, Pelz DM, Jones PM. Cervical spine motion: a fluoroscopic comparison of the AirTraq Laryngoscope versus the Macintosh laryngoscope. Anesthesiology 2009;111:97-101. [CrossRef]

5. Saracoglu KT, Eti Z, Gogus FY. Airtraq optical laryngoscope: advantages and disadvantages. Middle East J Anesthesiol 2013;22:135-416.

6. Nasim S, Maharaj CH, Malik MA, O' Donnell J, Higgins BD, Laffey JG. Comparison of the Glidescope and Pentax AWS laryngoscopes to the Macintosh laryngoscope for use by advanced paramedics in easy and simulated difficult intubation. BMC Emerg Med 2009;17;9:9.

7. Malik MA, O’Donoghue C, Carney J, Maharaj CH, Harte BH, Laffey JG. Comparison of the Glidescope, the Pentax AWS, and the Truview EVO2 with the Macintosh laryngoscope in experienced anaesthetists: a manikin study. $\mathrm{Br} J$ Anaesth 2009;102:128-34. [CrossRef]

8. Malik MA, Maharaj CH, Harte BH, Laffey JG. Comparison of Macintosh, Truview EVO2, Glidescope, and Airwayscope laryngoscope use in patients with cervical spine immobilization. Br J Anaesth 2008;101:723-30. [CrossRef]

9. Brimacombe J, Keller C, Kunzel KH, Gaber O, Boehler M, Puhringer F. Cervical spine motion during airway management: a cinefluoroscopic study of the posteriorly destabilized third cervical vertebrae in human cadavers. Anesth Analg 2000;91:1274-8. [CrossRef]

10. Turkstra TP, Craen RA, Pelz DM, Gelb AW. Cervical spine motion: a fluoroscopic comparison during intubation with lighted stylet, GlideScope, and Macintosh laryngoscope. Anesth Analg 2005;101:910-5. [CrossRef]

11. Hindman BJ, Santoni BG, Puttlitz CM, From RP, Todd MM. Intubation biomechanics: laryngoscope force and cervical spine motion during intubation with Macintosh and Airtraq laryngoscopes. Anesthesiology 2014;121:260-71. [CrossRef]

12. Li JB, Xiong YC, Wang XL, Fan XH, Li Y, Xu H, et al. An evaluation of the TruView EVO2 laryngoscope. Anaesthesia 2007;62:940-3. [CrossRef]

13. Barak M, Philipchuck P, Abecassis P, Katz Y. A comparison of the Truview blade with the Macintosh blade in adult patients. Anaesthesia 2007;62:827-31. [CrossRef]

14. Matsumoto S, Asai T, Shingu K. TruViewEVO2 videolaryngoscope. Masui 2007;56:213-7.

15. Matsumoto S, Asai T, Shingu K. Truview video laryngoscope in patients with difficult airways. Anesth Analg 2006;103: 492-3. [CrossRef] 
16. Kulkarni AP, Tirmanwar AS. Comparison of glottic visualisation and ease of intubation with different laryngoscope blades. Indian J Anaesth 2013;57:170-4. [CrossRef]

17. McElwain J, Laffey JG. Comparison of the C-MAC(R), Airtraq(R), and Macintosh laryngoscopes in patients undergoing tracheal intubation with cervical spine immobilization. $\mathrm{Br} \mathrm{J}$ Anaesth 2011;107:258-64. [CrossRef]

18. Arora S, Sayeed H, Bhardwaj N. A comparison of Truview EVO2 laryngoscope with Macintosh laryngoscope in routine airway management: A randomized crossover clinical trial. Saudi J Anaesth 2013;7:244-8. [CrossRef]

19. Maharaj CH, Buckley E, Harte BH, Laffey JG. Endotracheal intubation in patients with cervical spine immobilization: a comparison of macintosh and airtraq laryngoscopes. Anesthesiology 2007;107:53-9. [CrossRef]

20. Timanaykar RT, Anand LK, Palta S. A randomized controlled study to evaluate and compare Truview blade with Macintosh blade for laryngoscopy and intubation under general anesthesia. J Anaesthesiol Clin Pharmacol 2011;27:199-204. [CrossRef]

\section{APPENDIX}

Intubation Difficulty Scale

N1: The number of intubation attempts ( 0 point for the first attempt and 1 point for all others);

N2: The number of different anesthesiologists attempting intubation ( 0 point for no additional anesthesiologist and 1 for any additional anesthesiologist);

N3: The number of alternative intubation techniques that were needed ( 0 point, if no alternative intubation technique was needed, and changing blade type or using blind nasotracheal intubation or stylet increases N3 by 1 point);

N4: Glottic exposure as defined by the Cormack-Lehane Classification minus one;

N5: Need for extra lifting force during laryngoscopy ( 0 point if not needed and 1 point if needed);

N6: Using external laryngeal pressure ( 0 point if not needed and 1 point if needed);

N7: Position of the vocal cords ( 0 point for abduction, 1 point for adduction). 